\title{
Analgesic and antiinflammatory activities of the essential oil from Artemisia sieberi Besser
}

\author{
Elahe Pishgahzadeh¹, Hamed Shafaroodi², Jinous Asgarpanah ${ }^{\circledR 3^{*}}$
}

${ }^{1}$ Department of Pharmacology and Toxicology, Faculty of Pharmacy and Pharmaceutical Sciences, Tehran Medical Sciences, Islamic Azad University, Tehran, Iran, ${ }^{2}$ Department of Pharmacology, School of Medicine, Tehran University of Medical Sciences, Tehran, Iran, ${ }^{3}$ Department of Pharmacognosy, Faculty of Pharmacy and Pharmaceutical Sciences, Tehran Medical Sciences, Islamic Azad University, Tehran, Iran

\begin{abstract}
The analgesic activity of Artemisia sieberi oil was assessed by acetic acid-induced writhing test and Eddy's hot plate method; while the acute anti-inflammatory effect was investigated by inflammatory paw edema test in rats. The administration rout of the essential oil, standard drugs and the vehicle used in all assays was intraperitoneal injection. The 1 and $2.5 \mathrm{mg} / \mathrm{kg}$ doses of the studied oil significantly decreased the number of acetic acid-induced writhes in mice. The dose of $1 \mathrm{mg} / \mathrm{kg}$ of the oil also exhibited a central analgesic effect as evidenced by a significant increase in reaction time at several time points after $15 \mathrm{~min}$ treatment in the hot plate method. In addition, the $1 \mathrm{mg} / \mathrm{kg}$ dose of the oil significantly reduced carrageenan induced paw edema in rats at the first hour of the test by $72.7 \%$ inhibition and lasted to the third hour of the test by $74.3 \%$ inhibition found to be very close to that of the standard drug, diclofenac sodium $(50 \mathrm{mg} / \mathrm{kg})$. The major components of the oil were characterized as camphor $(31.2 \%)$ and 1,8-cineole (20.0\%). The results suggest that $A$. sieberi essential oil has a significant effect against acute inflammation and has central and peripheral anti-nociceptive effects.
\end{abstract}

Keywords: Artemisia sieberi drug effects. Essential oil/therapeutic use. Volatile oils/therapeutic use. Analgesics/administration and dosage. Anti-Inflammatory Agents Administration \& Dosage

\section{INTRODUCTION}

The genus Artemisia (Asteraceae) is one of the largest and most widely distributed ones comprising a variable number of species, ranging from 200 to over 400 and is predominantly distributed in the northern temperate region of the world (Tan, Zheng, Tang, 1998). Twenty nine species are reported in Iran, of which some are endemic (Rechinger, 1986; Mozaffarian, 1988).

A. sieberi is a native plant found in some parts of Iran including the south regions. This plant is exploited as a medicinal herb and locally called "Dermaneh" (Mozaffarian, 2006). As natural antiseptics, analgesic and anti-inflammatory agent, the flowering aerial parts have been commonly used in Iranian traditional medicine, as well as treating the painful menstruation, dyspepsia, arthralgia, fever, headache, common cold and healing wounds. Due to the widespread use of $A$. sieberi in Iranian traditional medicine for relieving and treating pain and inflammatory-based disorders, the anti-inflammatory activity of the plant extract has been previously evaluated. The plant extract with high doses $(>4000 \mathrm{mg} / \mathrm{kg})$ has shown anti-inflammatory effects in mice (Morshedi et al., 2011). Since the aerial parts of the plant contain high amount of essential oil $(2-4 \%, \mathrm{v} / \mathrm{w})$, we were prompted to evaluate the anti-inflammatory and anti-nociceptive effects of $A$. sieberi essential oil for the first time and investigate the pharmacological basis for the folkloric use of it as an anti-inflammatory and analgesic medicine. This study explores the anti-inflammatory and analgesic properties of A. sieberi oil through using various standard experimental test models. The oil was also analyzed by GC and GC-MS in order to identify the compounds potentially responsible for the observed properties. This is the first trial to address such ethno-pharmacological properties of $A$. sieberi essential oil in a comprehensive manner. 


\section{MATERIAL AND METHODS}

\section{Plant material}

Fresh aerial parts of $A$. sieberi were collected from Qotb-Abad County, Hormozgan Province, Iran: $\left(27^{\circ} 46^{\prime} 12^{\prime \prime} \mathrm{N}, 56^{\circ} 04^{\prime} 27^{\prime \prime} \mathrm{E}, 800 \mathrm{~m}\right)$ in May 2015. Specimens were identified by R. Asadpour and voucher was deposited in the Herbarium of Pharmaceutical Sciences Branch, Islamic Azad University (IAUPS), Tehran, under code number 312-AUPF.

\section{Essential oil extraction}

Freshly collected aerial parts were crushed and immediately submitted for hydrodistillation in a Clevengertype apparatus for 2 hours. At the end of distillation, the essential oil was collected, dried with anhydrous $\mathrm{Na}_{2} \mathrm{SO}_{4}$, and kept in glass vials at $-18{ }^{\circ} \mathrm{C}$ for further analysis.

\section{Experimental animals}

Throughout this study, Male NMRI mice (20-25 g) were used. Animals were housed in groups of 5-6 and were allowed free access to food and water except for the short time that they were removed from their cages for testing. All experiments were conducted between 10.00 a.m. and 13.00 p.m., at normal room light (12 h regular light/dark cycle) and temperature $\left(22 \pm 1{ }^{\circ} \mathrm{C}\right)$. All procedures were carried out based on the institutional guidelines for animal care and use (ethical approval number: 3183 ). Each mouse was used only once.

\section{Analgesic activity}

Acetic acid-induced writhes in mice: The acetic acidinduced writhing test was performed as originally described by Siegmund, Cadmus, and $\mathrm{Lu}$ (1957). Writhing test is a chemical method used to induce pain of peripheral origin by injection of irritant principles like phenylquinone or acetic acid in mice. Analgesic activity of the test compound is inferred from decrease in the frequency of writhing. This method was employed to evaluate the possible peripheral analgesic effects of $A$. sieberi essential oil.

Five groups of six mice were fasted overnight before the start of the experiment, while having free access to water. The vehicle, sweet almond oil $(10 \mathrm{mg} / \mathrm{kg})$ and the essential oil $(0.5,1,2.5$ and $5 \mathrm{mg} / \mathrm{kg})$ were administered by intraperitoneal injection to the first, second, third, fourth and fifth groups of the mice, respectively $30 \mathrm{~min}$ before the injection of acetic acid $(1 \%, 10 \mathrm{~mL} / \mathrm{kg})$. The mice were then placed in an observation box, and the number of writhes was counted for 30 min after acetic acid injection (Siegmund, Cadmus, Lu, 1957).

Hot plate test in mice: The hot plate test is commonly used for evaluating thermal pain sensitivity. It is a behavioral model of nociception where behaviors such as jumping and hind paw licking are elicited following a noxious thermal stimulus. Licking is a rapid response to painful thermal stimuli that is a direct indicator of nociceptive threshold. Jumping represents a more elaborated response with latency and encompasses an emotional component of escaping. The hot plate assay method was employed for the purpose of preferential assessment of a possible centrally mediated analgesic effect of $A$. sieberi essential oil (McDonald et al., 1946). Diclofenac sodium and morphine were also used as positive control substances. Five groups of six mice were fasted overnight before the start of the experiment, while having free access to water. For three consecutive days preceding the experiments, mice (20-25 g) were placed on a plate maintained at room temperature for $15 \mathrm{~min}$ each day. The vehicle (sweet almond oil, $10 \mathrm{~mL} / \mathrm{kg}$ ) was given to the first group by intraperitoneal injection. Diclofenac sodium $(50 \mathrm{mg} / \mathrm{kg})$, morphine $(5 \mathrm{mg} / \mathrm{kg})$ and the essential oil ( 1 and $2 \mathrm{mg} / \mathrm{kg}$ ) were also administered to the second to fifth groups by the same route. Each animal was then placed gently on a $55^{\circ} \mathrm{C}$ hot plate. Latency to exhibit nociceptive responses, such as licking paws or jumping off the hot plate, was determined 15, 30, 45 and 60 minutes after administration of the test substances or vehicle (McDonald et al., 1946).

\section{Anti-inflammatory activity}

Inflammatory paw edema in rats: Originally described by Winter, Risley \& Nuss (1962), inflammation induced by carrageenan is acute, non-immune, wellresearched, and highly reproducible. Cardinal signs of inflammation, hyperalgesia, and erythema develop immediately after subcutaneous injection of carrageenan, resulting from the activity of pro-inflammatory agents such as bradykinin, histamine, tachykinins, complement and reactive oxygen and nitrogen species. Such agents can be generated in situ at the site of insult or by infiltrating cells. Neutrophils readily migrate to the inflammation sites; and they can generate pro-inflammatory reactive oxygen and other species. The inflammatory response is usually quantified by increase in paw size (edema) which is maximal around $5 \mathrm{~h}$ post-carrageenan injection and is modulated by inhibitors of specific molecules within the inflammatory cascade. 
Acute anti-inflammatory activity was assessed based on the inhibition paw edema induced by the injection of $0.1 \mathrm{~mL} 2 \%$ carrageenan into the subplantar region of the right hind paw of the rat (Winter, Risley, Nuss, 1962). Male rats were divided into four groups of five, each of which separately received the vehicle, sweet almond oil $(10 \mathrm{~mL} / \mathrm{kg})$, Diclofenac sodium $(50 \mathrm{mg} / \mathrm{kg})$ and the essential oil (1 and $2 \mathrm{mg} / \mathrm{kg}$ ), intraperitoneally $1 \mathrm{~h}$ before the injection of carrageenan. Paw volume was measured after $0.5,1,2,3$ and $4 \mathrm{~h}$ after the carrageenan administration using a Plethysmometer (model LE 7500, Letica Scientific Instruments, manufactured in Spain).

\section{Statistical analysis}

The data were expressed as mean values \pm S.E.M. and tested using analysis of variance (ANOVA) followed by the multiple comparison test of Tukey-Kramer.

\section{Analysis of the essential oil}

Analysis of the essential oil sample was performed on a HP-6890 gas chromatograph (GC) equipped with a FID and a DB-5 capillary column, $30 \mathrm{~m} \times 0.25 \mathrm{~mm}$, $0.25 \mu \mathrm{m}$ film thickness, and temperature programmed as follows: $60-240{ }^{\circ} \mathrm{C}$ at $4{ }^{\circ} \mathrm{C} / \mathrm{min}$. The carrier gas $\mathrm{N}_{2}$ was at a flow of $2.0 \mathrm{~mL} / \mathrm{min}$; the temperatures of injector port and detector were $250^{\circ} \mathrm{C}$ and $300{ }^{\circ} \mathrm{C}$, respectively. Sample was injected by splitting with the split ratio of 1:10. The GC/MS analysis was performed on a HewlettPackard 6890/5972 system with a DB-5 capillary column (30 $\mathrm{m} \times 0.25 \mathrm{~mm} ; 0.25 \mu \mathrm{m}$ film thickness). The operating conditions were the same as described above but the carrier gas was He. Mass spectra were taken at $70 \mathrm{eV}$. The range of scan mass was from $40-400 \mathrm{~m} / \mathrm{z}$ at a sampling rate of $1.0 \mathrm{scan} / \mathrm{s}$. Quantitative data were obtained from the electronic integration of the FID peak areas. The oil components were identified by their retention time, retention indices, relative to $\mathrm{C}_{9}-\mathrm{C}_{28} \mathrm{n}$-alkanes, computer matching with the WILEY275.L library, as well as by comparing their mass spectra with those of authentic samples or with data already available in the literature (Adams, 1995; Swigar, Silverstein, 1981). The percentage of composition of the identified compounds was computed from the GC peaks areas without any correction factors; and it was calculated relatively.

\section{RESULTS}

Intraperitoneal administration of $A$. sieberi oil ( 0.5 , $1,2.5$ and $5 \mathrm{mg} / \mathrm{kg}$ ) decreased the number of acetic acid- induced writhes in mice compared to the animals received vehicle only (Figure 1). The best results were observed in 1 and $2.5 \mathrm{mg} / \mathrm{kg}$ doses of the oil. The analgesic effect induced by $A$. sieberi oil was not dose-related.

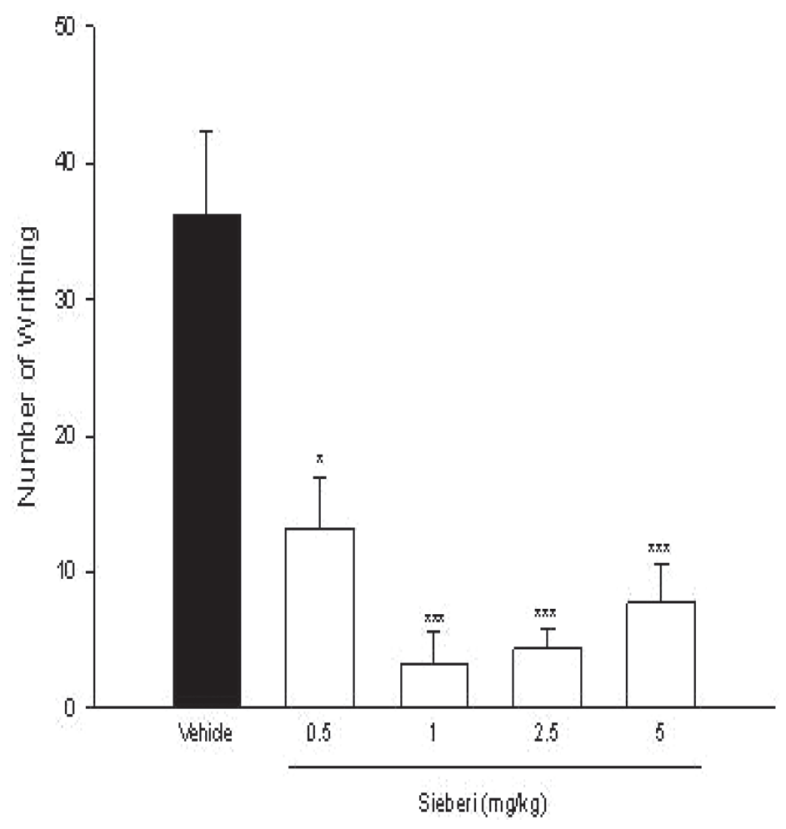

FIGURE 1 - Effect of $A$. sieberi essential oil on acetic acidinduced writhes in mice. Each value represents the mean \pm S.E.M. of eight mice. $* P<0.05, * * P<0.01$ and $* * * P<0.001$ compared to the control group using one-way ANOVA followed by Dunnett's multiple comparison test.

Through using the hot plate test, it was also shown that intraperitoneal administration of the oil $(1 \mathrm{mg} / \mathrm{kg})$ significantly prolonged the reaction time at several time points after 15 min treatment compared to the corresponding control groups (Figure 2).

The latency of nociception at $15 \mathrm{~min}$ was more than that of the standard drug diclofenac sodium, and less than that of the standard drug morphine; nevertheless, at 30,45 and $60 \mathrm{~min}$, the observed effect was considerably more than that of both standard drugs. Intraperitoneal administration of $A$. sieberi oil significantly prolonged the latency of inflammation in mice compared to the mice that received vehicle only.

The acute anti-inflammatory effect of $A$. sieberi essential oil in rat paw edema induced by carrageenan was tested using the intraperitoneally administered essential oil (Table I).

The essential oil ( 1 and $2 \mathrm{mg} / \mathrm{kg}$ ) as well as diclofenac sodium $(50 \mathrm{mg} / \mathrm{kg})$, significantly inhibited the carrageenan-induced rat paw edema formation. The best anti-inflammatory activity was observed in $1 \mathrm{mg} / \mathrm{kg}$ dose of the studied oil determined at the first hour of the test 
15 min
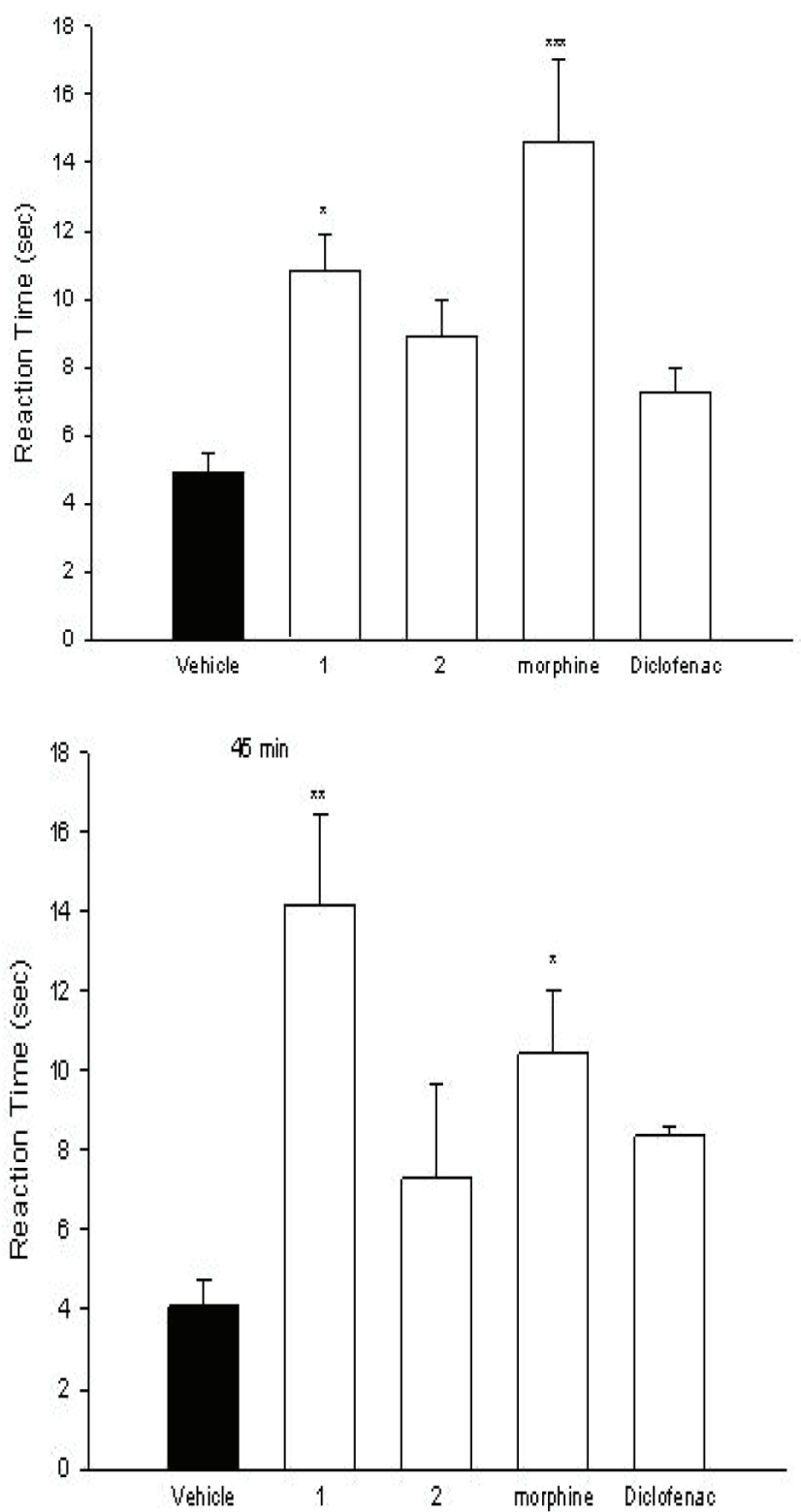

30 min

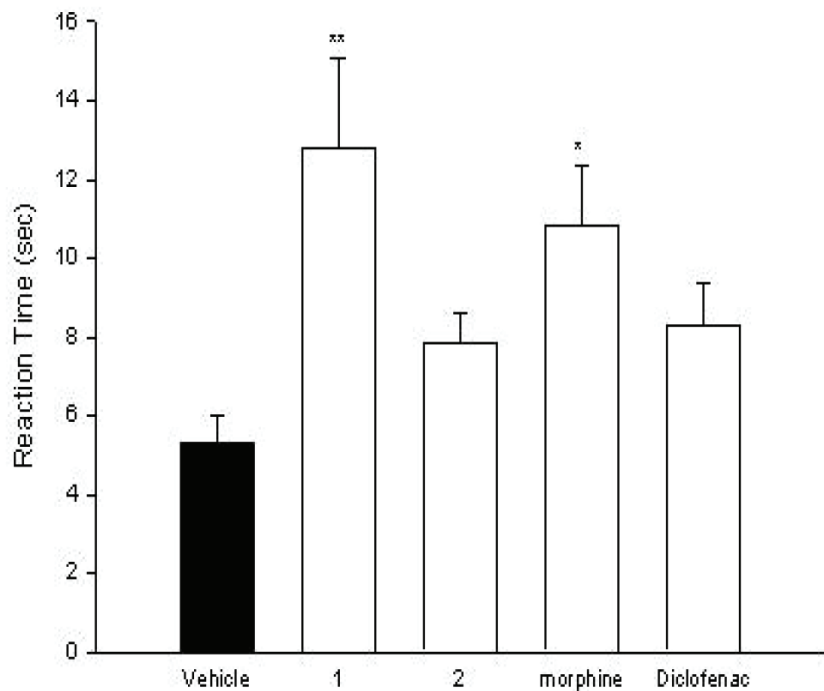

$60 \mathrm{~min}$

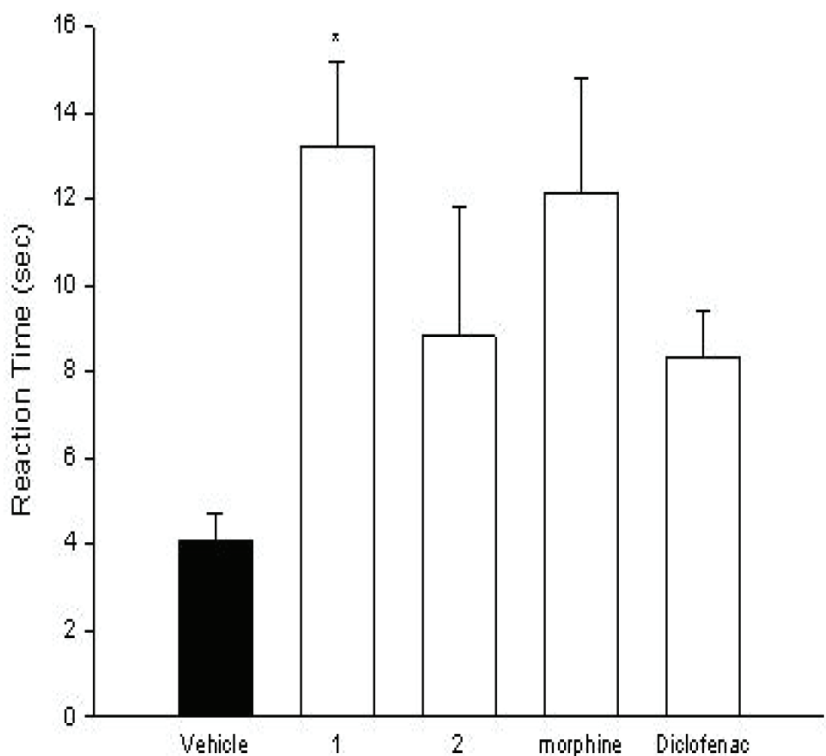

FIGURE 2 - Effects of $A$. sieberi ( 1 and $2 \mathrm{mg} / \mathrm{kg}$ ) essential oil on the latency time $(15,30,45$ and $60 \mathrm{~min})$ of mice exposed to the hot plate test. Each value represents the mean \pm S.E.M. of eight mice. ${ }^{*} P<0.05, * * P<0.01$ and $* * * P<0.001$ compared to the control group using one-way ANOVA followed by Dunnett's multiple comparison test.

TABLE I - Effect of A. sieberi essential oil on the inflammation induced by carrageenan

\begin{tabular}{lcccccc}
\hline \multirow{2}{*}{ Group } & \multirow{2}{*}{ Doses $(\mathbf{m g} / \mathbf{k g})$} & \multicolumn{5}{c}{ Inhibition of edema at various time intervals (\%) } \\
\cline { 3 - 7 } & & $\mathbf{0 . 5} \mathbf{~ h}$ & $\mathbf{1 ~ h}$ & $\mathbf{2} \mathbf{~ h}$ & $\mathbf{3 ~ h}$ & $\mathbf{4} \mathbf{~ h}$ \\
\hline Control & 10 & - & - & - & - & - \\
Essential oil & 1 & $49.1 \pm 4.5$ & $72.7 \pm 12.1$ & $72.5 \pm 8.4$ & $74.3 \pm 8.3$ & $58.0 \pm 15.6$ \\
& 2 & $56.8 \pm 15.9$ & $57.6 \pm 1.7$ & $39.9 \pm 7.4$ & $44.3 \pm 7.1$ & $81.4 \pm 7.0$ \\
Diclofenac sodium & 50 & $33.7 \pm 5.5$ & $74.7 \pm 8.3$ & $90.8 \pm 4.6$ & $64.0 \pm 13.3$ & $39.5 \pm 8.3$ \\
\hline
\end{tabular}

Each value represents the mean \pm .E.M. of five mice. 
TABLE II - GC-MS analysis of $A$. sieberi essential oil

\begin{tabular}{lccc}
\hline \multicolumn{1}{c}{ Compound $^{\mathbf{a}}$} & $\mathbf{K I}^{\mathbf{b}}$ & $\mathbf{K I}^{\mathbf{c}}$ & Percentage \\
\hline 1. Artemisia triene & 931 & 929 & 0.1 \\
2. Camphene & 950 & 954 & 1.7 \\
3. Yomogi alcohol & 996 & 999 & 1.3 \\
4. - -Terpinene & 1011 & 1017 & 0.5 \\
5. $\rho$-Cymene & 1028 & 1026 & 1.3 \\
6. 1,8-Cineol & 1036 & 1033 & 20.0 \\
7. $\gamma$-Terpinene & 1060 & 1062 & 0.9 \\
8. Artemisia alcohol & 1089 & 1084 & 2.3 \\
9. $\rho$-Menth-2-en-1-ol & 1137 & 1140 & 0.5 \\
10. Camphor & 1143 & 1146 & 31.2 \\
11. Borneol & 1166 & 1169 & 2.4 \\
12. Terpinene-4-ol & 1179 & 1177 & 3.4 \\
13. Carvone & 1241 & 1243 & 0.8 \\
14. cis-Chrysanthenyl acetate & 1259 & 1262 & 0.7 \\
15. Bornyl acetate & 1291 & 1289 & 1.2 \\
16. Jasmone & 1399 & 1394 & 1.2 \\
17. $\beta$-Caryophyllene & 1432 & 1428 & 0.6 \\
18. Bicyclogermacrene & 1501 & 1494 & 0.5 \\
19. Spathulenol & 1581 & 1577 & 4.6 \\
20. Caryophyllene oxide & 1587 & 1583 & 1.5 \\
\hline Total & & & 76.7 \\
\hline
\end{tabular}

${ }^{\mathrm{a}}$ Compounds listed in order of elution. ${ }^{\mathrm{b} K I}$ (Kovats index) measured relative to $n$-alkanes $\left(\mathrm{C}_{9}-\mathrm{C}_{28}\right)$ on the non-polar DB-5 column under condition listed in the Materials and Methods section. ${ }^{c} \mathrm{KI}$, (Kovats index) from literature $(10,11) .<<$ insert the citation $>>$

(peak of edema formation) by $72.7 \%$ inhibition and lasted to the third hour of the experiment by $74.3 \%$ inhibition. While the most potent inhibitory effect of the standard drug diclofenac sodium observed at the second hour of the test by $90.8 \%$ inhibitory activity and the decreased effects were observed at the third and fourth hours.

A. sieberi essential oil was analyzed by GC and $\mathrm{GC} / \mathrm{MS}$ to determine the possible compounds responsible for the observed analgesic and anti-inflammatory activities. Hydro-distillation of $A$. sieberi aerial parts gave a pale yellow oil with a significant odor and a yield of $1.8 \%, \mathrm{v} / \mathrm{w}$. As shown in Table II, twenty components were identified in the oil, which totally presented about $76.7 \%$ of the whole. The major constituents of the oil were camphor $(31.2 \%)$ and 1,8 -cineole $(20.0 \%)$.

\section{DISCUSSION}

Different preparations made from A. sieberi aerial parts are commonly used in ethnobotanical practices for the treatment of pain and inflammation in Iran. In this study, we evaluated the efficacy of the essential oil of aerial parts since the volatile constituents comprise the main components of this plant. Results observed in the present study showed it to be the first report describing the analgesic and anti-inflammatory activities of $A$. sieberi oil. The results indicated that the essential oil decreased abdominal constriction, indicating the inhibition of expression of prostaglandin synthesis by the cyclooxygenase pathway (Duarte, Nakamura, Ferreira, 1988). In addition, its effect on the peripheral and central levels was observed, suggesting a characteristic biphasic licking response (Hunskaar, Hole, 1987). The central action was confirmed in the hot plate test, showing maximal effect after 15 minutes of the response.

Phytochemical results indicated that the analgesic effects of $A$. sieberi essential oil might be due to its 1,8-cineole and camphor content. The major constituents of the oil were camphor (31.2\%) and 1,8-cineole (20.0\%); however most articles reported $\alpha$ and $\beta$-thujones as the main components of essential oils (Mahboubi, 2017).

These two components have comprised more than half of the oil composition. As a natural analgesic, camphor has a long history and widespread use. It has been reported as a potent anti-nociceptive compound in some biological assays (Martínez et al., 2009; Xu, Blair, Clapham, 2005). Camphor has been shown to desensitize sensory nerves by acting a member of transient receptor potential (TRP) channel superfamily, the heat-sensitive TRP vanilloid subtype 3 (TRPV3). Xu, Blair, Clapham 
(2005) have demonstrated that camphor also activated heterologously expressed TRPV1 which was recognized as the main molecular mechanism of some analgesics like capsaicin, of course, more rapidly and completely than capsaicin and the other ones. On the other hand, camphor could activate and desensitize the capsaicin receptor (TRPV1) while inhibiting the TRPA1 (ankyrin-repeat TRP1) channel, both of which are heavily expressed in nociceptive sensory neurons.

1,8-Cineole was also shown to have considerable analgesic activity which is related to the activation and desensitization of the TRPM8 (TRP channel M8) while inhibition of the TRPA1 channel, both of which are highly expressed in nociceptive sensory neurons. 1,8-cineole was reported as a rare natural antagonist of TRPA 1 having both analgesic and anti-inflammatory effects possibly due to its inhibition of TRPA1 (Takaishi et al., 2012). The analgesic activity of 1,8-cineole has been also examined in vivo in two different pain models, the acetic acid-induced writhing response and the formalin test in mice (Santos, Rao, 2000). Since the results have shown marked analgesic activity, it could be concluded that the analgesic activity of the studied oil could also be related to its high 1,8-cineole content. Since the effective dose of orally administrated 1,8-cineole to kill pain has been evaluated as 100 to $400 \mathrm{mg} / \mathrm{kg}$, the difference between the administration way and the presence of other main active components in the oil, especially the camphor could confirm the significant analgesic activity of $A$. sieberi essential oil at low dose of $1 \mathrm{mg} / \mathrm{kg}$.

A. sieberi essential oil also showed activity against acute inflammation. Carrageenan-induced edema has been commonly used as an experimental animal model for acute inflammation and believed to be biphasic. The results for paw edema showed noticeable reduction at both doses of 1 and $2 \mathrm{mg} / \mathrm{kg}$, especially the $1 \mathrm{mg} / \mathrm{kg}$ dose. The inhibitory activity shown by $A$. sieberi oil $(1 \mathrm{mg} / \mathrm{kg})$ during a $4 \mathrm{~h}$ period in the carrageenan-induced paw inflammation test was somewhat better to that exhibited by the group treated with diclofenac sodium, especially after the first hour. The anti-inflammatory activity of $A$. sieberi oil could be related to the inhibition of NO formation/release. Many reports have suggested that peripherally produced by different nitric oxide synthase (NOS) isoforms, NO contributes to edema formation (Rivot, MontagneClavel, Besson, 2002). Pharmacological evaluation of the essential oils containing camphor and 1,8-cineole in animal models also revealed that these two components play a major role in the anti-inflammatory activity and provide further evidence suggesting that camphor and/or 1,8-cineole-producing species are potentially anti- inflammatory agents (Peana et al., 2002). Since studies demonstrated that the injection of carrageenan into the rat paw induced the release of bradykinin, which later induced the biosynthesis of prostaglandin and other autacoids that were responsible for the formation of the inflammatory exudates (Ueno et al., 2000), perhaps camphor and/or 1,8-cineole in the oil inhibited the biosynthesis of prostaglandins.

These results justify the use of $A$. sieberi in the Iranian traditional medicine; and the plant essential oil could be a potential candidate as an analgesic and antiinflammatory agent, especially to be used as a major active ingredient in balms, ointments and creams supplied as topical analgesics and ant inflammations.

\section{ACKNOWLEDGMENTS}

Supports from the Tehran Medical Sciences, Islamic Azad University are gratefully appreciated.

\section{REFERENCES}

Adams RP. Identification of essential oil components by gas chromatography/mass spectroscopy. Carol Stream: Allured Publishing; 1995.

Duarte IDG, Nakamura M, Ferreira SH. Participation of the sympathetic system in acetic acid-induced writhing in mice. Braz J Med Biol Res. 1988;21(2):341-3.

Hunskaar S, Hole K. The formalin test in mice: dissociation between inflammatory and noninflammatory pain. Pain. 1987;30(1):103-4.

Mahboubi M. Artemisia sieberi Besser essential oil and treatment of fungal infections. Biomed Pharmacother. 2017;89:1422-30.

Martínez AL, González-Trujano ME, Pellicer F, López-Muñoz FJ, Navarette A. Antinociceptive effect and GC/MS analysis of Rosmarinus officinalis L. essential oil from its aerial parts. Planta Med. 2009;75(5):508-11.

McDonald AD, Woolfe G, Bergel F, Morrison AL, Rinderknecht $\mathrm{H}$. Analgesic action of pethidine derivatives and related compounds. Brit J Pharmacol. 1946;1:4-14.

Morshedi A, Dashti Rahmatabadi MH, Dehghan Harati M, Bagherinasab MA, Salami AS. The effect of Artemisia sieberi Besser. on inflammatory and neurogenic pain in mice. J Med Plants. 2011,10(40): 48-57. 
Mozaffarian V. Study and recognition of Iranian Artemisia spp. Tehran: Tehran University of Sciences Press; 1988.

Mozaffarian V. A dictionary of Iranian plant names. Tehran: Farhang Moaser Press; 2006.

Peana AT, D’Aquila PS, Panin F, Serra G, Pippia P, Moretti MD. Antiinflammatory activity of linalool and linalyl acetate constituents of essential oils. Phytomedicine. 2002;9(8):721-6.

Rechinger KH. Flora Iranica. Graz: Akademische Druck-u Verlagsanstalt; 1986.

Rivot JP, Montagne-Clavel J, Besson JM. Subcutaneous formalin and intraplantar carrageenan increase nitric oxide release as measured by in vivo voltammetry in the spinal cord. Eur J Pain. 2002;6(1):25-34.

Santos FA, Rao VS. Antiinflammatory and antinociceptive effects of 1,8-cineole a terpenoid oxide present in many plant essential oils. Phytother Res. 2000;14(4):240-4.

Siegmund E, Cadmus R, Lu G. A method for evaluating both non-narcotic and narcotic analgesics. Proc Soc Exp Biol Med. 1957;95(4):729-31.

Swigar AA, Silverstein RM. Monoterpenes. Milwaukee: Aldrich Chemical Company; 1981.
Takaishi M, Fujita F, Uchida K, Yamamoto S, Sawada Shimizu M, Hatai Uotsu C, et al. 1,8-cineole, a TRPM8 agonist, is a novel natural antagonist of human TRPA1. Mol Pain. 2012;8:86.

Tan RX, Zheng WF, Tang HQ. Biologically active substances from the genus Artemisia. Planta Med. 1998;64(4):295-302.

Ueno A, Naraba H, Ikeda Y, Ushikubi F, Murata T, Naramiya $\mathrm{S}$, et al. Intrinsic prostacyclin contributes to exudation induced by bradikinin or carrageenan: a study on the paw edema induced in IP-receptor-deficient mice. Life Sci. 2000;66(12):PL155PL60.

Winter CA, Risley EA, Nuss GW. Carrageenin-induced edema in hind paws of the rat as an assay for antiinflammatory drugs. Proc Soc Exp Biol Med. 1962;111:544-7.

Xu H, Blair NT, Clapham DE. Camphor activates and strongly desensitizes the transient receptor potential vanilloid subtype 1 channel in a vanilloid-independent mechanism. J Neurosci. 2005;25(39): 8924-37.

Received for publication on $15^{\text {th }}$ May 2017 Accepted for publication on $16^{\text {th }}$ May 2018 